\title{
Anchor Areas to Improve Conservation and Increase Connectivity within the Brazilian "Mesopotamia of Biodiversity"
}

\author{
Christiane Gonçalves Dall'Aglio Holvorcem ${ }^{1, *}$, Leandro Reverberi Tambosi ${ }^{2}$, \\ Milton Cezar Ribeiro ${ }^{3}$, Sabrina Costa ${ }^{4} \&$ Carlos Alberto Bernardo Mesquita ${ }^{4}$
}

\author{
${ }^{1}$ Instituto BioAtlântica, Porto Seguro, BA, Brazil \\ ${ }^{2}$ Laboratório de Ecologia de Paisagens e Conservação - LEPaC, Departamento de Ecologia, Instituto de Biociências - IB, \\ Universidade de São Paulo - USP, São Paulo, SP, Brazil \\ ${ }^{3}$ Laboratório de Ecologia Espacial e Conservação - LEEC, Departamento de Ecologia, \\ Universidade Estadual Paulista - UNESP, Rio Claro, SP, Brazil \\ ${ }^{4}$ Instituto BioAtlântica, Rio de Janeiro, RJ, Brazil
}

\begin{abstract}
We propose a new methodology based on graph theory for selecting high priority "anchor areas" to which conservation and restoration activities could be "attached", in order to maximize the impact of the available resources on biodiversity conservation and on increasing the landscape functional connectivity. Anchor areas are defined as habitat fragments which are among the largest present in the landscape and the most important for maintaining the landscape functional connectivity, as quantified by the Integral Index of Connectivity (IIC). Recommended actions include increasing the protection of the anchor areas and restoring smaller fragments in their neighborhood whose size and placement make them convenient "stepping stones" in the establishment of ecological corridors between the anchor areas and other areas with a potentially high biological importance. We illustrate our approach with an analysis of the sizes and functional connections between remaining forest fragments in the "Mesopotamia of Biodiversity", a portion of Brazilian Atlantic Forest with an especially rich biodiversity situated between the rivers Jequitinhonha and Doce.
\end{abstract}

Key words: Conservation Site Prioritization, Landscape Restoration, Landscape Connectivity, Graph-Based Metrics, Bahia Bioregion, Atlantic Forest.

\section{Introduction}

Habitat loss and fragmentation due to agricultural and urban expansion are the most important threats to biodiversity worldwide (Fahrig 2003). Atlantic Forest originally coved 150 million hectares, but because of the intensified forest destruction nowadays only 12 to $16 \%$ of original forest remains (Ribeiro et al. 2009). Due to the large extent of the Atlantic Forest biome, there is an urgent need to identify high-priority areas where conservation and restoration actions would be focused. Although some species occurrence data (especially about threatened and endemic species) are available for a number of forest fragments and protected lands in the Atlantic Forest (Bencke et al. 2006; Devenish et al. 2009; Paese et al. 2010), for most forest fragments there is a lack of information about their conservation status and biological data are scarce or available for only few species.

\footnotetext{
*Send correspondence to: Christiane G.D. Holvorcem Instituto BioAtlântica, Praça da Bandeira, 100, sala 1, Centro,CEP 45810-000, Porto Seguro, BA, Brazil e-mail: chris@bioatlantica.org.br
}

One of the possible approaches to deal with the absence of biological data over extensive areas is to utilize descriptive landscape metrics as surrogates to biodiversity indicators (Martensen et al. 2008). This idea is especially promising in fragmented landscapes below the habitat loss threshold (30\% of habitat cover), where not only the habitat area, but also the spatial configuration of remnants are important for maintaining biodiversity (Fahrig 2003). For instance, larger fragments, with more regular shapes, and well-connected to other fragments, tend to exhibit higher species diversity than small, elongated, and isolated fragments (Martensen et al. 2008). Landscape analyses based on graph theory are becoming popular in ecological studies due to their ability to link landscape structure (composition and spatial arrangement of patches) and ecological characteristics of the various species. A graph is a set of nodes, with links connecting pairs of nodes. In a graph representation of the landscape, each habitat fragment is represented by a graph node (Urban \& Keitt 2001), and attributes (such as fragment area) can be assigned to each node (see Appendix 
A in the Additional Supporting Information available at www.abecol.org.br).

In this paper, we proposed a new method to select highpriority areas to improve conservation and increase habitat connectivity through forest restoration in a high-biodiversity region in the Atlantic Forest. The proposed method makes use of the Integral Index of Connectivity (IIC; Pascual-Hortal \& Saura, 2006), and allows the stakeholders to evaluate absolute and relative contributions of each habitat patch for improving local and regional biodiversity. The set of high-priority areas selected by the new method includes a subset consisting of large patches which are among the most relevant to maintain the functional connectivity of the landscape. We propose that the areas in this subset be used as "anchor areas", to which protection and restoration actions could be "attached", in an attempt to maximize the impact of restoration and conservation initiatives on preserving biodiversity and improving the functional connectivity of the landscape.

\section{Study area}

Our study area is located between the rivers Jequitinhonha and Doce, in the Bahia bioregion of Atlantic Forest
(Ribeiro et al. 2009), (Figure 1), (see also Appendix B in the Additional Supporting Information at www.abecol. org.br for details). A coastal strip within the study area in southern Bahia state is considered a World Natural Heritage Site. Because of these peculiar characteristics, some institutions which are active in the protection and restoration of biodiversity in the region between the Jequitinhonha and Doce rivers have started referring to it as the "Mesopotamia of Biodiversity" (MB). In recent years, this region has become the target of various initiatives aiming to protect forest fragments and restoring Permanent Protection Areas (riparian buffer zones protected by the Brazilian Forest Code, known by their acronym in Portuguese, APP) (Metzger et al. 2010), in order to create ecological corridors. Prevailing land uses in the MB include homogeneous eucalyptus plantations and cultivation of perennial (coffee, papaya) and some annual species (sugar cane, cassava).

\section{Methods}

The input data for our landscape analyses was obtained from the database produced by Fundação SOS Mata Atlântica and Brazil's National Institute for Space Research (SOS Mata Atlântica \& INPE 2010). By analyzing the remaining forest fragments within the $\mathrm{MB}$, we observed that they

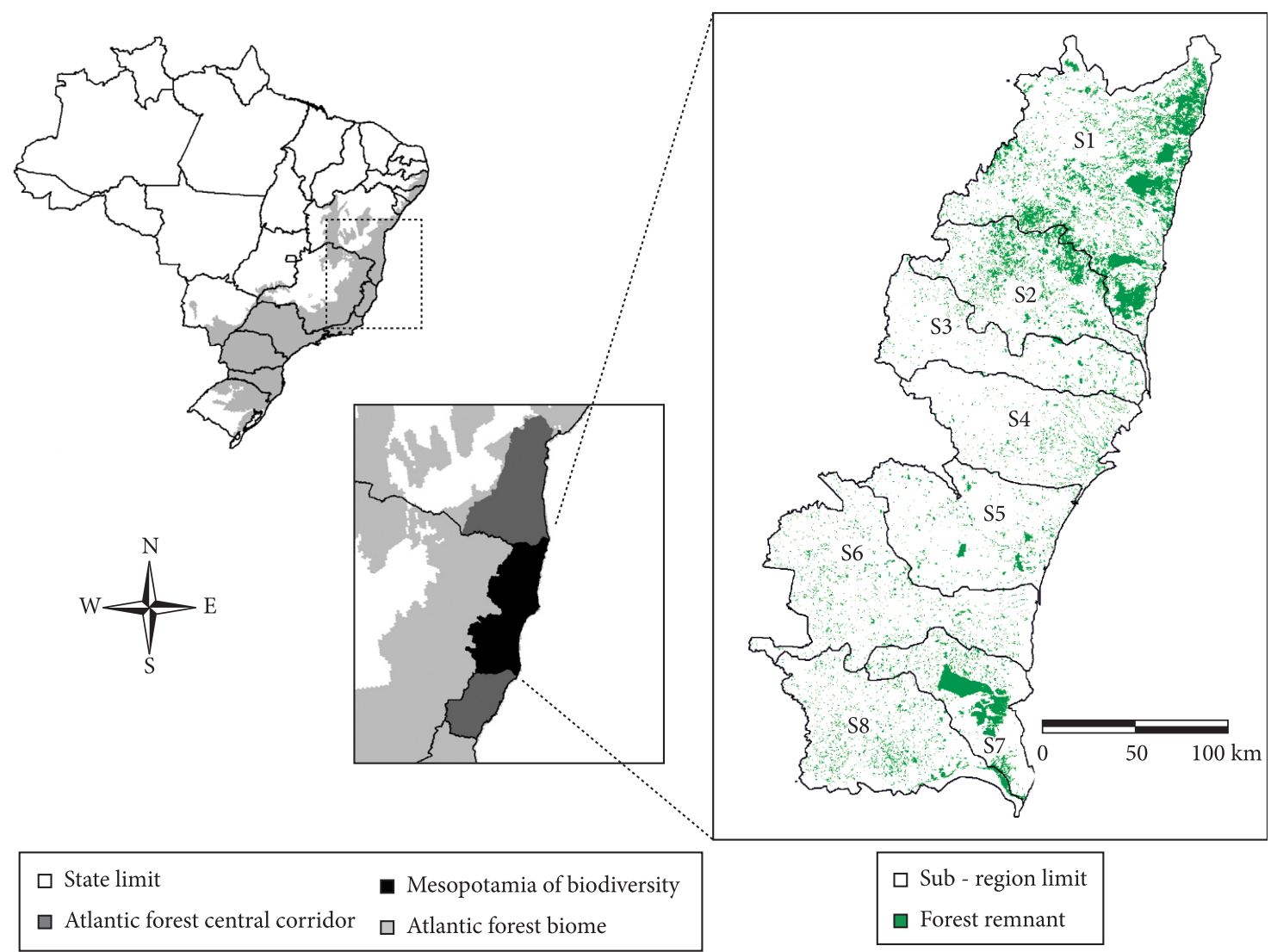

Figure 1. Location of the Mesopotamia of Biodiversity within the Central Corridor of the Atlantic Forest. 
Table 1. Values of landscape metrics for each sub-region of the Mesopotamia of Biodiversity. \%FC = percentage of forest cover, $\mathrm{NP}=$ number of patches, $\mathrm{NC}=$ number of components, $\mathrm{MCA}=$ mean component area, $\mathrm{LCA}=$ largest component area, $\mathrm{LPA}=$ largest patch area, MPA = mean patch area, MPI = mean path isolation. Standard deviations are given in parentheses.

\begin{tabular}{cccrccrrrc}
\hline $\begin{array}{c}\text { Sub- } \\
\text { region }\end{array}$ & $\begin{array}{c}\text { Sub-region } \\
\text { area (ha) }\end{array}$ & \% FC & NP & NC & $\begin{array}{c}\text { MCA } \\
\text { (ha) }\end{array}$ & $\begin{array}{c}\text { LCA } \\
\text { (ha) }\end{array}$ & $\begin{array}{c}\text { LPA } \\
\text { (ha) }\end{array}$ & $\begin{array}{c}\text { MPA } \\
\text { (ha) }\end{array}$ & $\begin{array}{c}\text { MPI } \\
\text { (m) }\end{array}$ \\
\hline S1 & $1,161,400$ & 21.6 & 2693 & 804 & $310(3006)$ & 49,486 & 24,205 & $93(832)$ & $265(352)$ \\
S2 & 524,800 & 21.2 & 1677 & 609 & $183(1833)$ & 31,277 & 24,205 & $66(683)$ & $312(407)$ \\
S3 & 481,400 & 3.6 & 829 & 528 & $33(94)$ & 1,649 & 1,649 & $21(70)$ & $627(731)$ \\
S4 & 542,600 & 3.5 & 838 & 518 & $36(99)$ & 1,688 & 324 & $22(35)$ & $568(692)$ \\
S5 & 597,300 & 3.9 & 830 & 526 & $44(181)$ & 2,907 & 2,400 & $28(123)$ & $627(699)$ \\
S6 & 786,200 & 3.5 & 2109 & 1229 & $22(38)$ & 568 & 370 & $13(21)$ & $450(483)$ \\
S7 & 363,000 & 22.2 & 756 & 398 & $189(2517)$ & 49,077 & 23,408 & $99(1,097)$ & $399(524)$ \\
S8 & 596,700 & 8.2 & 2164 & 1053 & $41(321)$ & 9,834 & 4,107 & $20(128)$ & $357(335)$ \\
\hline
\end{tabular}

exhibit a large variation in size and degree of isolation, with some portions of the MB being dominated by small, isolated fragments, and other portions containing large, well-connected fragments (Figure 1 and Table 1). If a landscape configuration analysis were performed considering the entire MB as a single unit, the selected "anchor areas" for conservation would tend to be concentrated on the portions of the MB containing large, well-connected fragments. We consider it important to spatially distribute anchor areas for conservation across all the portions of the MB, including those which contain few or no large, well-connected fragments. To achieve this, we divided the MB into eight sub-regions (hereafter S1 to S8; Figure 1). This subdivision used fifth-order hydrographic sub-basins, as determined by the National Water Agency of Brazil (see Ribeiro et al. 2011 and references therein). To characterize the region, seven landscape metrics were computed at patch and landscape scales (see Appendix C in the Additional Supporting Information).

To analyze the landscape according to the graph theory approach, we considered the forest patches as the graph nodes, using the patch area as the node attribute. We adopted a "dispersal range" of $400 \mathrm{~m}$, meaning that two fragments separated by less than $400 \mathrm{~m}$ were considered as functionally connected. Even though our assumed dispersal range is larger than the observed dispersal ranges $(<100 \mathrm{~m})$ recorded for forest-dependent understory birds in the Serra do Mar sub-region (Awade \& Metzger 2008), other studies in the Atlantic Forest suggest dispersal ranges very similar or larger than the value adopted here (Crouzeilles et al. 2010). Assuming a much larger dispersal range would result in very few (or even a single) functionally connected components in the landscape, indicating that landscape structure would not limit the flow of organisms in the landscape. On the other hand, assuming a much smaller dispersal range would lead to a few (or no) functionally connected patches, indicating that the individuals would not be able to move between patches. This suggests us that these two situations do not occur for many species present in the $\mathrm{MB}$, so that our chosen dispersal range appears to be reasonable for a subset of the species present in that region. We note that the dispersal range adopted here is of the same order as the mean isolation estimated for the forest fragments within the Bahia bioregion (Ribeiro et al. 2009) and within the MB (Table 1).

The software Conefor Sensinode 2.5.8 (Saura \& Torné 2009) was used to calculate six metrics based on the graph-theory approach for each sub-region: number of components (NC), mean component area (MCA), largest component area (LCA), and the importance of each fragment in the graph structure according to the three fractions of the IIC index (varIICintra, varIICconnector and varIICflux). A value of NC smaller than the number of patches (NP) indicates the presence of functionally connected patches. The MCA and LCA values also indicate how large are the functionally connected areas in the landscape.

To avoid using highly correlated metrics to identify the most important areas for maintaining the biodiversity, we calculated Spearman correlations between the various landscape metrics at patch level within each sub-region. Those indices that were not correlated $(p>0.05)$ or had low correlation $(\rho<0.5$ and $p<0.05)$ were kept in the analysis.

The varIICintra index depends only on patch attributes, and does not take into account any connections between patches or the dispersal capabilities of organisms (Saura \& Rubio 2010). Since in our analysis the only node attribute is patch area, the value of varIICintra is directly related to the area of each patch, and from now on will be referred to simply as "patch area" (PA). See Appendix D in the Additional Supporting Information for details about this topic.

We defined three criteria to rank the importance of patches based on the their classification by quantiles: a) patches with the highest values (fifth quantile) of both PA and varIICconnector were considered "important according to the CONAREA criterion" (which we will also refer to as "anchor areas"), due to their size and importance as connecting elements; b) patches with the highest values (fifth quantile) of PA, but with lower values (first to fourth quantiles) of varIICconnector were considered "important 
according to the AREA criterion"; and c) patches with the highest values (fifth quantile) of varIICconnector, but with lower values (first to fourth quantiles) of PA were rated as "important according to the CON criterion" (which we will also refer to as "important connector elements").

\section{Results}

The eight sub-regions S1 through S8 showed large variations in area and percent forest cover, and all sub-regions were highly fragmented (Table 1). Sub-regions S1, S2, and S7 have the highest percentage of forest cover ( $\% \mathrm{FC} 20 \%)$, the highest MCA and the highest values of the LCA among the sub-regions, corresponding to the presence of large, functionally connected forest areas (Figure 2 and Table 1). Despite the presence of large components, these three sub-regions also contain a large number of small, isolated patches (Figure 2 and Table 1). The other five sub-regions have much lower \%FC (3-8\%), distributed among a large number of fragments, with a low MCA. The number of components for these sub-regions is larger than half the number of fragments, indicating that a large number of patches are not functionally connected in the landscape,
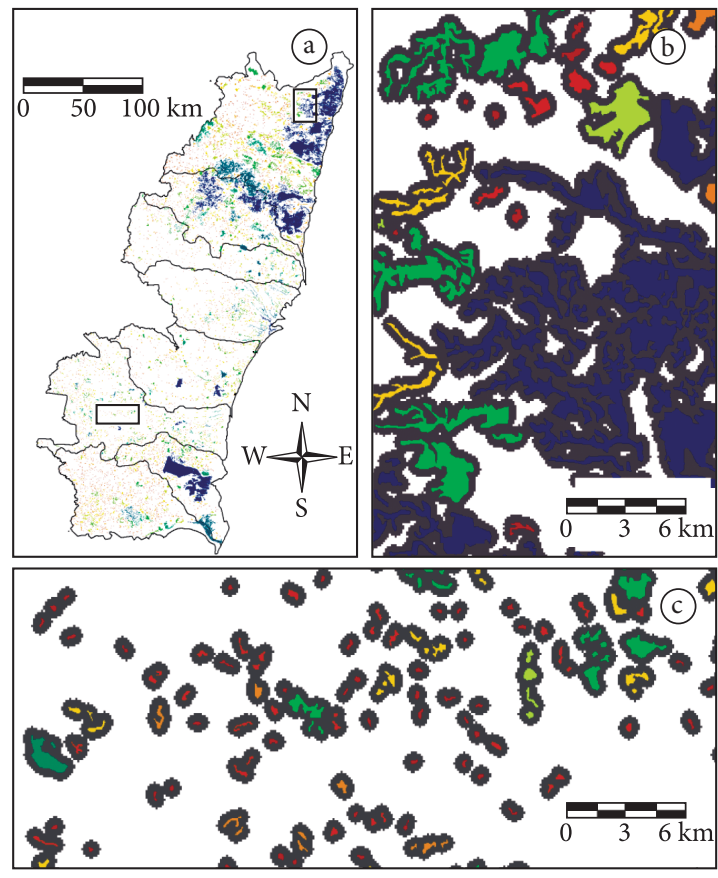

Relative com ponent size in sub-region Min $\operatorname{Max}$

$\square$ Sub - region limit $\square 400$ meter from patch edge

Figure 2. Grouping of functionally connected forest fragments into landscape components (a). In each sub-region, the grouping into components was made considering only the fragments in that sub-region. Details (b) and (c) show results on typical portions of sub-regions S1 and S6, respectively. Relative component areas within each sub-region are indicated by a color scale. mainly due to the high values of mean patch isolation (Figure 2 and Table 1).

The analysis shows that, in the three sub-regions with highest $\% \mathrm{FC}(\mathrm{S} 1, \mathrm{~S} 2$, and S7), more than $70 \%$ of the remaining forest area is contained in fragments classified as important by the CONAREA criterion (Table 2 and Figure 3), indicating that the large forest remnants in these sub-regions are also extremely important for maintaining the connectivity between several smaller fragments. Sub-regions S3 through S6 had roughly half of their forest cover contained in fragments classified as important by the AREA criterion (Table 2), which suggests that most of the larger fragments in these sub-regions do not take part in very extensive components, or that, when they are part of large components, they are not the most important connector elements of these components. The low percentage of forest cover in each sub-region represented by patches classified as important by the CON criterion, and their low mean patch area (Table 2) underline the importance of these small remnants for the maintenance of functional connectivity in all eight sub-regions, since their loss would result in the break-up of large components.
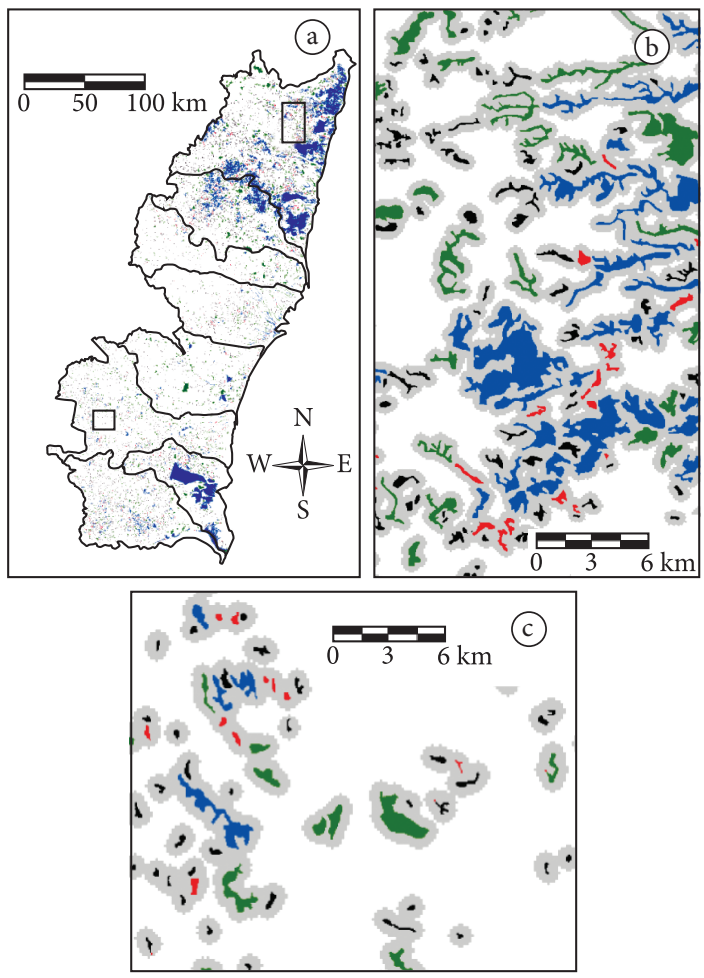

$$
\begin{aligned}
& \square \text { Sub - region limit } \square 400 \text { meter from patch edge } \\
& \text { Patch classification } \\
& \square \text { Area } \square \text { Conarea } \square \text { CON } \square \text { Other patches }
\end{aligned}
$$

Figure 3. Results of the classification of fragments according to the AREA, CON, and CONAREA criteria within each subregion of the Mesopotamia of Biodiversity (a). Details (b) and (c) show results on typical portions of sub-regions S1 and S6, respectively). 
Table 2. Mean area, standard deviation of area, and percent forest cover represented by fragments classified as important by the AREA, $\mathrm{CON}$, and CONAREA criteria. Areas are presented in hectares.

\begin{tabular}{|c|c|c|c|c|}
\hline Sub-region & Classification & Mean patch area & Area s.d. & $\%$ Forest cover \\
\hline \multirow[t]{3}{*}{$\mathrm{S} 1$} & AREA & 121 & 155 & 14 \\
\hline & CONAREA & 718 & 2628 & 73 \\
\hline & $\mathrm{CON}$ & 21 & 12 & 2 \\
\hline \multirow[t]{3}{*}{ S2 } & AREA & 96 & 159 & 15 \\
\hline & CONAREA & 491 & 2137 & 72 \\
\hline & $\mathrm{CON}$ & 14 & 8 & 2 \\
\hline \multirow[t]{3}{*}{ S3 } & AREA & 76 & 163 & 54 \\
\hline & CONAREA & 76 & 66 & 17 \\
\hline & CON & 6 & 4 & 4 \\
\hline \multirow[t]{3}{*}{ S4 } & AREA & 65 & 46 & 39 \\
\hline & CONAREA & 89 & 67 & 25 \\
\hline & $\mathrm{CON}$ & 8 & 8 & 5 \\
\hline \multirow[t]{3}{*}{ S5 } & AREA & 88 & 220 & 50 \\
\hline & CONAREA & 183 & 386 & 25 \\
\hline & $\mathrm{CON}$ & 5 & 7 & 3 \\
\hline \multirow[t]{3}{*}{ S6 } & AREA & 36 & 25 & 43 \\
\hline & CONAREA & 57 & 57 & 19 \\
\hline & $\mathrm{CON}$ & 5 & 5 & 6 \\
\hline \multirow[t]{3}{*}{ S7 } & AREA & 80 & 101 & 11 \\
\hline & CONAREA & 1195 & 4093 & 81 \\
\hline & $\mathrm{CON}$ & 10 & 9 & 1 \\
\hline \multirow[t]{3}{*}{ S8 } & AREA & 43 & 45 & 25 \\
\hline & CONAREA & 115 & 431 & 47 \\
\hline & CON & 8 & 4 & 5 \\
\hline
\end{tabular}

\section{Discussion}

All sub-regions within the study area present a high degree of fragmentation and habitat loss, where $\% \mathrm{FC}$ varied from $3.6 \%$ (S4, S6) to $22.2 \%$ (S7), being below the extinction threshold, suggested to be at $30 \%$ habitat cover, where severe species loss is expected due to the effects of habitat loss and fragmentation (Fahrig 2003; Martensen et al. unpublished results). This result indicates that the maintenance of high biodiversity in these areas is under a severe threat. Even though Atlantic Forest areas with these characteristics are considered to have a low potential for biodiversity conservation (Martensen et al. 2008), the MB still exhibits a high diversity of species, including endemic and threatened species (Devenish et al. 2009). This high diversity may result from the region not having yet reached its relaxation time of species loss due to habitat loss and fragmentation, and maybe the current biodiversity is distributed according to the previous landscape configuration (Metzger et al. 2009). This is the phenomenon known as time-lagged response, which encompasses an extinction debit in the future, where part of the currently present species is expected to be lost in a long-term trend of species loss (Tilman et al. 1994). The fact that most of the habitat loss and fragmentation took place within a relatively short time (last 60 years) and the presence of several large protected areas may also help explain the persistence of high biodiversity in the MB up to the present epoch.
Forest restoration actions in the sub-regions containing large components, where the connectivity between fragments is high, present a high potential for success, since connectivity is one of the essential elements in restoration projects (Ribeiro et al. 2011; Gama et al. unpublished results), with better connected landscapes having a higher potential for recolonization of restored areas (Pardini et al. 2010). Restoration actions can also be planned to promote the connection between pairs of large components which are close to each other (Figure 2, upper right panel). This can maximize the positive effects of habitat restoration on the improvement of landscape connectivity at both local (Martensen et al. 2008) and regional (Rodrigues et al. 2010; Gama et al. unpublished results) scales.

Fragments classified as important by the AREA criterion have a potential to achieve higher biodiversity levels compared to smaller patches (Turner \& Tjorve 2005), and therefore could act as sources of individuals for the recolonization of neighboring fragments and of restored areas near their boundaries, even though they cannot be considered the most important elements for maintaining the connectivity within large components in the landscape.

Fragments classified as important by the CON criterion are often of strategic importance for conservation, despite their small dimensions, since their particular spatial position allows them to serve as connection points between larger fragments. This gives them a high potential for harbouring 
a high diversity of species, as observed by Martensen et al. (2008) for understory bird species in a fragmented landscape in the Serra do Mar bioregion. Besides, these fragments are important elements for maintaining connectivity within each sub-region, since their removal would result in the break-up of the largest sub-graphs (Saura \& Pascual-Hortal 2007). The conservation of these fragments (e.g., as private reserves) would be essential to maintain the flux of organisms in the landscape, reducing the isolation of larger fragments (Boscolo \& Metzger, 2011).

The fragments rated as important by the CONAREA criterion may act both as strong sources of individuals of many species and as key elements for the maintenance of the flux of organisms over large functionally connected areas. Restoration actions in the components which contain such fragments have a great potential for success and an excellent cost-benefit ratio (Pardini et al. 2010; Gama et al. unpublished results). We propose to use these fragments as "anchor areas", to which conservation and restoration actions would be attached. As the demand for conservation and habitat restoration exceeds the available resources to meet it, we can define targets based on both financial support (i.e. amount of money available) and goals defined by stakeholders. After clearly defining the conservation and restoration targets, several alternatives can be selected to achieve the desired results. Specifically, actions which increase the protection of forest habitats (e.g., creation of new public and private protected areas) would be focused on the CONAREA fragments, while forest restoration actions would be concentrated in $\mathrm{CON}$ fragments belonging to the components containing the CONAREA fragments. In this way, the connectivity among all or some of the fragments which are part of these components would be re-established, using the CON fragments as structural corridors (if completely restored) or stepping stones (if partially restored), creating new ecological corridors connecting the "anchor areas" to other "important" fragments (e.g., AREA fragments or other CONAREA fragments). The use of the available resources for implementing restoration actions could be optimized in order to increase the amount of physically connected forest area per unit restored area in CON fragments and/or their surroundings. It should be noted that some "strategic" CON fragments may be conveniently placed for the establishment of protected areas (e.g., within private lands, which according to Brazilian environmental laws could become Private Natural Heritage Reserves, Permanent Protection Areas, or Legal Reserve areas), which should be encouraged whenever feasible.

This proposed methodology for allocating the available resources to conservation and restoration actions would help ensure that some of the major potential sources of organisms (the "anchor areas") are protected and connected to other potentially relevant areas for biodiversity conservation. The analysis presented here for the MB could easily be replicated for other biologically important regions.
From a methodological point of view, the criteria used in this work to select high priority areas for biodiversity conservation allow the identification of key elements in landscapes with conservation states ranging from well-preserved to highly fragmented. These criteria may be modified to fit the characteristics of particular target species, or the available resources for conservation and/ or restoration actions (Gama et al. unpublished results). The number of fragments rated as "anchor areas" may also be suitably tuned depending on the objective of the analyses, by adjusting the number of quantiles for the various landscape indices. The dispersal range could also be tuned to give higher priority to the conservation of very sensitive species in a well-preserved region, or to identify key areas for species with a high dispersal range. This flexibility of landscape analyses based on graph theory brings a new, relatively simple, replicable, and ecologically robust contribution to the arena of discussion about how to rank areas for conservation or restoration. This can guide stakeholders by devising conservation strategies which need to be adapted to suit a particular regional context, and by optimizing the application of generally limited resources for conservation and restoration actions.

\section{Acknowledgements}

The authors thank the coordinators of SCGIS-Brasil for the invitation to publish the present work, the anonymous reviewers for their valuable suggestions to improve the manuscript, $\mathrm{CNPq}$ for the financial support to LRT, and Santiago Saura for making his program ConeforSensinode version 2.5.8 available to us before its official release.

\section{References}

Awade M \& Metzger JP, 2008. Using gap-crossing capacity to evaluate functional connectivity of two Atlantic rainforest birds and their response to fragmentation. Austral Ecology, 33:863-871. http://dx.doi. org/10.1111/j.1442-9993.2008.01857.x

Bencke GA et al. (eds.), 2006. Áreas Importantes para a Conservação das aves no Brasil. São Paulo: SAVE Brasil. Parte 1 - Estados do Domínio da Mata Atlântica.

Boscolo D \& Metzger JP, 2011. Isolation determines patterns of species presence in highly fragmented landscapes. Ecography, in press. http://dx.doi.org/10.1111/j.1600-0587.2011.06763.x

Crouzeilles R, Lorini ML \& Grelle CEV, 2010. Deslocamento na matriz para espécies da Mata Atlântica e a dificuldade da construção de perfis ecológicos. Oecologia Australis, 14(4):872-900.

Devenish C et al., 2009. Important Bird Areas Americas Priority sites for biodiversity conservation. Quito: BirdLife International. BirdLife Conservation Series, n. 16.

Fahrig L, 2003. Effects of habitat fragmentation on biodiversity. Annual Review of Ecology, Evolution and Systematics, 34:487-515. http://dx.doi.org/10.1146/annurev. ecolsys.34.011802.132419 
Fundação SOS Mata Atlântica \& Instituto Nacional de Pesquisas Espaciais - INPE, 2010. Atlas dos Remanescentes Florestais da Mata Atlântica. Available from: <http://mapas.sosma. org.br/>. Access in: 30 jul. 2011.

Martensen AC, Pimentel RG \& Metzger JP, 2008. Relative effects of fragment size and connectivity on bird community in the Atlantic Rain Forest: implications for conservation. Biological Conservation, 141:2184-2192. http://dx.doi. org/10.1016/j.biocon.2008.06.008

Metzger JP et al., 2009. Time-lag in biological responses to landscape changes in a highly dynamic Atlantic forest region. Biological Conservation, 142:1667-1177. http:// dx.doi.org/10.1016/j.biocon.2009.01.033

Metzger JP et al., 2010. Brazilian law: full speed in reverse? Science, 329(5989):276-277.

Paese A et al., 2010. Fine-scale sites of global conservation importance in the Atlantic Forest of Brazil. Biodiversity and Conservation, 19:3445-3458. http://dx.doi.org/10.1007/ s10531-010-9906-x

Pardini R et al., 2010. Beyond the Fragmentation Threshold Hypothesis: Regime Shifts in Biodiversity Across Fragmented Landscapes. PLOS One, 5:e13666. PMid:21060870. PMCid:2965145. http://dx.doi.org/10.1371/journal. pone. 0013666

Pascual-Hortal L \& Saura S, 2006. Comparison and development of new graph-based landscape connectivity indices: towards the prioritization of habitat patches and corridors for conservation. Landscape Ecology, 21(7):959-967. http:// dx.doi.org/10.1007/s10980-006-0013-Z

Ribeiro MC et al., 2009. The Brazilian Atlantic Forest: How much is left, and how is the remaining forest distributed? Implications for conservation. Biological
Conservation, 142:1141-1153. http://dx.doi.org/10.1016/j. biocon.2009.02.021

Ribeiro MC et al., 2011. The Brazilian Atlantic Forest: a shrinking biodiversity hotspot. In: Zachos FE \& Habel JC (eds.). Biodiversity Hotspots. Berlin: Springer-Verlag. http:// dx.doi.org/10.1007/978-3-642-20992-5_21

Rodrigues RR et al., 2010. Large-scale ecological restoration of high-diversity tropical forests in SE Brazil. Forest Ecology and Management, 261(10):1605-1613. http://dx.doi.org/10.1016/j. foreco.2010.07.005

Saura S \& Pascual-Hortal L, 2007. A new habitat availability index to integrate connectivity in landscape conservation planning: comparison with existing indices and application to a case study. Landscape and Urban Planning, 83:91-103.

Saura S \& Rubio L, 2010. A common currency for the different ways in which patches and links can contribute to habitat availability and connectivity in the landscape. Ecography, 33:523-537.

Saura S \& Torné J, 2009. ConeforSensinode 2.2: A software package for quantifying the importance of habitat patches for landscape connectivity. Environmental Modelling \& Software, 24:135-139. http://dx.doi.org/10.1016/j. envsoft.2008.05.005

Tilman D et al., 1994. Habitat destruction and the extinction debt. Nature, 371:65-66. http://dx.doi.org/10.1038/371065a0

Turner WR \& Tjorve E, 2005. Scale-dependence in species-area relationships. Ecography, 28(6):721-730. http://dx.doi. org/10.1111/j.2005.0906-7590.04273.x

Urban D \& Keitt T, 2001. Landscape connectivity: a graphtheoretic perspective. Ecology, 82:1205-1218. http://dx.doi. org/10.1890/0012-9658(2001)082[1205:LCAGTP]2.0.CO;2

Received: July 2011

First Decision: September 2011

Accepted: November 2011 